\title{
ORIGEN Y FORMACIÓN DEL LEÍSMO EN EL ESPAÑOL DEL PARAGUAY. ENSAYO DE UN MÉTODO
}

El concepto de causación múltiple, definido y fundamentado con rigor por Yakov Malkiel ${ }^{1}$ aunque utilizado con anterioridad por otros autores ${ }^{2}$, es a mi parecer, como ya lo he manifestado en varias ocasiones ${ }^{3}$, un instrumento metodológico extremadamente útil para analizar diacrónicamente los procesos genéticos que han dado lugar a determinados rasgos lingüísticos en la Romania Nueva y, más concretamente, en el español americano, ámbitos en los cuales la complejidad de los factores estructurales y sociohistóricos en presencia en las diferentes etapas históricas hace desaconsejable el enfoque monocausal de la mayor parte de la problemática lingüística en ellos planteada.

Me propongo en este trabajo presentar un caso particular en el que se ha utilizado la metodología de la causación múltiple para el estudio genético de un rasgo del español americano en una zona geográfica determinada con resultados que, creo, confirman la fertilidad de dicho procedimiento de análisis y la conveniencia de que el mismo sea aplicado a otros aspectos, similares en su problemática, de la misma área. Me re-

1 «Multiple versus simple causation in linguistic change», en To Honor Roman Jakobson, t. II, La Haya, 1967, págs. 1.228-1.246.

2 Por ejemplo, DAmaso Alonso, La fragmentación fonética peninsular (Enciclopedia Lingüística Hispánica, t. I, Suplemento), Madrid, 1962.

3 Véase en especial Planteamientos y necesidades actuales en los estudios lingüisticos afro-hispanoamericanos, ahora incluido en Estudios lingüisticos hispánicos, afrohispánicos y criollos, Madrid, Gredos, 1978, págs. 185-215. 
fiero, concretamente, al fenómeno del leísmo en el español hablado en Paraguay y a sus posibles causas determinantes ${ }^{4}$.

Mientras que el leísmo (y también, lógicamente, el loísmo y el laísmo) han sido brillante y repetidamente estudiados en lo que se refiere al español europeo tanto en su aspecto histórico ${ }^{5}$ como en sus manifestaciones actuales ${ }^{6}$, abordándose en especial las cuestiones que se relacionan con los factores causales que han producido la conformación presente, diastrática y diatópica, de los fenómenos examinados ${ }^{7}$, no ha corrido la misma suerte el leísmo que se encuentra en algunas zonas hispanoamericanas. Desde C. F. Mac Hale ${ }^{8}$ hasta Salvador Fernández Ramírez ${ }^{9}$ y desde Rufino José Cuervo ${ }^{10}$ hasta Rafael Lapesa ${ }^{11}$ se ha venido, en efecto, repitiendo, con generalización errónea, que «desde México hasta Chile nadie

4 Posiblemente el fenómeno en cuestión se encuentre también en otras zonas geográficas que comparten con el Paraguay numerosos rasgos fonéticos, morfosintácticos y léxico semánticos como son las áreas de Corrientes y Misiones en la República Argentina y la comarca de Santa Cruz de la Sierra en Bolivia. Cfr. Vermiro Ayala Gauna, «El español de Corrientes», en Boletín de Filología (Montevideo), 10, 1963-1964, págs. 115-126 y HERNANDo SANABRIa FERNANDEZ, aInfluencia del guaraní en el habla popular de Santa Cruz (Bolivia)», en Revista de la Universidad Autónoma de Santa Cruz de la Sierra, 7 (12), 1958, págs. 43-47.

5 E. Gessner, «Das spanische Personalpronomen», en ZRPh, 17, 1893, págs. 1-54; Rufino Jose CuERVo, «Los casos enclíticos y proclíticos del pronombre de tercera persona en castellano», en Romania, 24, 1895, págs. 95-113 y 219-263 (aumentado y corregido en Obras de Rufino José Cuervo, Bogotá, Instituto Caro y Cuervo, 1950, págs. 175-242); E. StaAp, Etudes sur les pronoms abrégés en ancien espagnol, Uppsala, 1906; E. Cotarelo y Mori, Sobre el «le y el «law. Cuestión gramatical, Madrid, 1910; Ramón Menéndez Pidal, Cantar de Mio Cid, I, Madrid, 1908, § 130; William B. BreWER, «Extent of verbal influence and choice between $l e$ and $l o$ in Alphonsine prose», en Hispanic Review, 38, 1970-1972, págs. 133-146, etc.

6 Salvador Fernandez Ramfrez, Gramática Española, I, Madrid, 1951; Esbozo de una nueva Gramática de la Lengua Española, Madrid, 1973; J. M. Blecua y J. Alcina Franch, Gramática Española, Madrid, 1975; D. M. PERLMUTTER, «Les pronoms objects en espagnol: un exemple de la nécessité de contraintes de surface en syntaxe», en Langages, 14, 1969, págs. 81-133; JACOUES SCHMIDERY, «Grammaire et statistique: l'alternance le/lo dans l'expression de l'object direct en espagnol», en Et. Ling. Ap., 6, 1972, págs. 37-58, etc.

7 Véanse, en especial, los excelentes trabajos de RAPaEl LAPESA, «Sobre los origenes y la evolución del lefsmo, laísmo y loísmo», en Festschrift Walther von Wartburg, Tübingen, 1968, págs. 523-551 y «Evolución sintáctica y forma lingüística interior en español», en Actas del XI Congreso Internacional de Lingüistica y Filología Románicas, I, Madrid, 1968, págs. 131-150, y también el muy útil y agudo de Francisco Marcos MarfN, «Usos anómalos y aparentemente anómalos de los pronombres átonos: Metodologia», en Cuadernos de Investigación Filológica (Logroño, España), 2 (2), 1976, págs. 27-62.

8 Diccionario razonado de modos de bien decir, Nueva York, 1930, pág. 146.

9 Ob. cit., en nota 6.

10 Art. cit., en nota 5.

11 Art. cit., en primer lugar en nota 7, pág. 524. 
dice le vi, le conocí» ${ }^{12} \mathrm{o}$, en otros términos, que en el español de América (como en el de Andalucía y Canarias) no existe el fenómeno del leísmo y ello explica que, en las monografías generales que abordan esta temática, se haya dejado sistemáticamente de lado el hecho, no por limitado menos importante, de que, contra lo generalmente afirmado, explícita o implícitamente, sí existen áreas de leísmo en el español americano así como también empleos esporádicos de este rasgo lingüístico, condicionados por factores estilísticos o sociolinguísticos, en zonas hispanoamericanas no leístas ${ }^{13}$.

Dejando de lado ahora este último hecho, que no afecta al desarrollo de nuestra investigación sino de modo muy tangencial, constatamos que, en realidad y cuando menos, se da como indudable la presencia de leísmo en Ecuador y Paraguay en la conocida obra de Kany sobre sintaxis hispanoamericana ${ }^{14}$, áreas a las que hay que añadir, por otra parte, los territorios leístas argentinos estudiados por B. E. Vidal de Battini ${ }^{15}$.

Prescindiré, sin embargo, en este trabajo, de las zonas ecuatorianas y argentinas de leísmo y lo centraré en las consideraciones de los datos paraguayos, que he podido estudiar directamente como consecuencia de mi estadía en el país, desempeñando funciones diplomáticas, durante más de dos años y que, además, revisten un mayor interés como consecuencia de la escasísima y, en ocasiones, muy poco confiable bibliografía disponible en relación con la fisonomía general ${ }^{16} \mathrm{y}$, más concretamente, morfosintáctica ${ }^{17}$ del español hablado en el Paraguay ${ }^{18}$.

12 Loc. cit., en nota 8.

13 Para este último fenómeno en general véase Juanita Carfora, $\propto L o$ and $l e$ in American Spanish», en Hispania, 52 (2), 1968, págs. 300-302. Para un caso particular, cfr. HANS-DIETER PAUfLeR, «Quelques observations sur l'emploi des pronoms personnels dans la variante cubaine de la langue espagnole», en Actele celui de al XII-lea Congres Internaţional de Lingvistica şi Filologie Romanica, II, Bucarest, 1971, páginas 1.159-1.164.

14 Charles Kany, Sintaxis hispanoamericana, Madrid, 1969, págs. 134-135.

15 Berta Elena Vidal dB Batrini, «Zonas de leísmo en el español de la Argentina», en Communications et Rapports du Premier Congrès International de Dialectologie Générale, II, Lovaina, 1964, págs. 160-163.

16 El trabajo, pretendidamente de conjunto, de LUIS DE GASPERI, «Presente y futuro de la lengua española en el Paraguay», en Presente y Futuro de la Lengua Española, I, Madrid, 1964, págs. 127-133 es prácticamente inutilizable. Las páginas que dedica al Paraguay y a su situación lingüística B. MaLMBerg, en La América Hispanohablante (Madrid, 1970, págs. 253-285) son, por su parte, extremadamente superficiales y, en no pocas ocasiones, erróneas, además, de parciales e incompletas en numerosos aspectos. Lo mismo puede afirmarse del trabajo del mismo autor, Notas sobre la fonética del español en el Paraguay, Lund, 1947. Sobre este último tema véanse las precisiones, bastante correctas, de P. V. Cassano, en sus artículos «The influence of Guarani on the phonology of the Spanish of Paraguay», en Studia Linguistica, 26, 1972, págs. 106-112 y «Substratum hypothesis concerning the Spanish of Paraguay», en Neophilologus, 55 (1), 1971, págs. 4144. 
Las características diatópicas, diastráticas y funcionales del leísmo paraguayo actual presentan los perfiles que expongo a continuación, basados en los datos recogidos directa y personalmente en encuestas, tanto programadas como informales, realizadas prácticamente en todo el país durante los años 1977 y 1978.

Funcionalmente la forma le es empleada, además de como objeto indirecto singular, como objeto directo singular masculino y femenino, tanto en los casos caracterizados por las notas (+ persona) o (+ animado) como en los que poseen las notas (- persona) o (- animado). Tam. bién se emplea le para los casos de objeto directo plural, y ello de modo absolutamente general ya que se encuentra esta forma referida a sustantivos masculinos, femeninos o neutros con las notas ( \pm persona) y ( \pm animado). Como se puede comprobar, el leísmo paraguayo no se da, contra lo que exponen Kany ${ }^{19}$ y B. Usher de Herreros ${ }^{20}$, solamente cuando se refiere a personas. A diferencia del leísmo peninsular europeo, en el que ésta es la característica normal del fenómeno ${ }^{21}$, el leísmo paraguayo se extiende además a la designación de cosas y ello tanto en singular como en plural y del mismo modo es masculino como en femenino o en neutro, empleándose en todos los casos la forma le. Se trata, en resumen de un leísmo individualizado por dos rasgos esenciales, totalmente diferentes de los que se encuentran en el leísmo europeo ( $\mathrm{y}$, al parecer, también en otras zonas hispanoamericanas): su absoluta generalidad ${ }^{22}$, abarcando referentes ( \pm humano), ( \pm animado), ( \pm masculino), ( \pm singular $),$ y su

17 Hay algunos datos en H. W. TeSsen, "Some aspects of the Spanish of Asunción", en Hispania, 57, 1974, págs. 935-937 y también en la tesis, aún inédita, de J. KetTle-Williams, A contribution to the study of the influence of Guarani on the Spanish of Asunción (1970). Observaciones valiosas, aunque con metodología y enfoque excesivamente simplistas, pueden encontrarse en BEATRIZ UsHER DE HERREROS, «Castellano Paraguayo. Notas para una gramática contrastiva castellano-guaraní, en Suplemento Antropológico. Universidad Católica (Asunción), 11 (1-2), 1976, págs. 29-123.

18 Bibliografías útiles sobre este tema, aunque solamente de interés parcial dada su dedicación casi exclusiva a los problemas derivados del bilingüismo español-guaraní, son B. Meliá, «Bibliografía sobre el bilinguiismo en el Paraguay», en Estudios Paraguayos, 2 (2), 1974, págs. 73-82 y GrazzIElla CoRvalan, Estudios sociolingüísticos en el Paraguay, Asunción, 1976. Véase ahora, con un enfoque más abarcador, mi trabajo «Materiales para el estudio sociohistórico de la problemática linguística del $\mathrm{Pa}$ raguay», en Thesaurus (Bogotá), 33, 1978.

19 Loc. cit., en nota 14.

20 Ob. cit., en nota 17 , págs. 52-53.

21 Véanse especialmente los trabajos de R. Lapesa y F. Marcos Marín citados en nota 7 .

22 Lógicamente, la influencia escolar y la presión normativa dan lugar, como veremos, en los estratos superiores de la sociedad paraguaya al manejo correcto de los pronombres personales átonos mientras que, en los estratos inferiores de la misma, se producen frecuentes ultracorrecciones en su empleo, algunas de cuyas manifestaciones recoge B. USHER DE HERRERos (ob. cit., pág. 53). 
invariabilidad formal ya que el morfema le funciona en el español paraguayo como única forma de objeto directo (y por supuesto, indirecto) para la totalidad de los casos posibles sintácticamente, sean cuales fueren el género, el número y la caracterización semántica del sustantivo a que es referido ${ }^{23}$.

Diatópicamente, no he apreciado diferencias en el empleo de la forma le como objeto indirecto y directo en ninguna zona del país respecto a los rasgos funcionales caracterizadores expuestos anteriormente.

Desde el punto de vista diastrático el leísmo paraguayo, tal como lo he descrito, se encuentra en los isolectos ${ }^{24}$ más distanciados de la norma linguiística regional ${ }^{25}$ en la totalidad de sus registros orales y escritos y en los isolectos medios y superiores en los registros orales fundamentalmente (aunque también se dan casos en el registro escrito) y en circunstancias preferentemente no formales si bien, en ocasiones formales, se pueden encontrar también casos de leísmo, sobre todo referidos a sustantivos caracterizados por las notas (+ humano) (+ animado) y (+ singular) ${ }^{26}$. Las variables sexo y edad no parecen determinar modificaciones relevantes en los resultados obtenidos en mis encuestas.

23 Las modalidades del leísmo paraguayo aquí descritas pueden ser apreciadas en los siguientes ejemplos, extraídos de Los Monólogos de José-Luis Appleyard (Asunción, Colección Oñondivepa, 1973) obra en la que, según hace constar en su prólogo B. Meliá, es muy exacta la transcripción del castellano paraguayo coloquial: "Y así para lo pasajero, que le desea [la azafata del aparato] felí viaje y cuanto pa va a tardar y que tiene teléfono si se quiere llamar a cualquier parte. Y mucho gente habla por teléfono y también se le llama a ello" (pág. 40); «...y tiene todo su torre iluminada pero cuando yo le ví parece que no é tan alta como vo eperá» (pág. 40); «un billete medio viejo ya, pero no etaba roto. Masiado bien me acuerdo que saqué y le puse ahí... (pág. 77); "Y entonce mi primo me recordó que su mamá o sea mi tía é también mi maína y tengo que pascuar por ella... y entonce, a la do de la mañana me subí en el caballo y me juí a la casa y a la do y media por ahí llegué y le deperté para pascuarle y ella me abrazón (pág. 99), etc.

24 Empleo aquí la terminología que, con base en los trabajos de W. A. Stewart (por ejemplo, "Continuity and change in American Negro dialects", en Florida $F$. L. Reporter, 6 (1), 1968, págs. 3-4,14-16, 18), ha sido posteriormente desarrollada en las investigaciones de D. BiCKERTON (On the structure of polylectal grammars, en Monograph Series on Languages and Linguistics, Georgetown University, 25, 1972, págs. 1742 y otros estudios).

25 Véanse, sobre este tema, JuAn M. LOPE Blanch, «El concepto de prestigio y la norma lingüística del español", en Anuario de Letras (México), 10, 1972, págs. 29-46 y JOSÉ PEDRo RONA, «Normas locales, regionales, nacionales y universales en la América española», en $N R F H, 22$ (2), 1973, págs. 310-321.

26 Téngase en cuenta, para la mejor inteligencia de la significación de los que hemos llamado aquí isolectos bajos, medios y superiores, que en el Paraguay actual la competencia lingüística en español parece estar en correlación directa y significativa con la estratificación socioeconómica, tanto en ambientes urbanos como rurales. Véanse los datos que sobre este tema proporciona Algunos aspectos del rendimiento escolar relacionados con el bilingüismo, Buenos Aires, 1978. 
La única hipótesis que, en la bibliografía disponible hasta el momento actual, ha intentado explicar genéticamente un estado de cosas como el aquí descrito en relación con el leísmo paraguayo es, bastante lógicamente, la que apela a la interferencia guaraní sobre el español paraguayo en este punto concreto. Aunque, a diferencia de lo que ocurre con la interferencia del castellano sobre las estructuras lingüísticas del guaraní ${ }^{27}$, el proceso inverso y paralelo, es decir la interferencia del guaraní sobre las estructuras lingüísticas del castellano paraguayo, no ha sido aún estudiado con amplitud, rigor y profundidad salvo muy escasas ocasiones ${ }^{28}$ es evidente que, prolongando una línea de investigación bien conocida, aplicada a otras áreas bilingües hispanoamericanas ${ }^{29}$, muchos rasgos del castellano paraguayo parecen ser susceptibles de explicación desde una postura teórica basada en el influjo adstratístico del guaraní, lengua hablada por la casi totalidad de la población del Paraguay ${ }^{30}$.

Este ha sido, en efecto, el rumbo metodológico seguido, respecto al leísmo paraguayo, por B. Usher de Herreros en su trabajo Castellano paraguayo. Notas para una gramática contrastiva castellano-guarani ${ }^{31}$. Según la autora ${ }^{32}$, el factor causal al que se debe atribuir fundamentalmente este rasgo del español del Paraguay es la interferencia sobre el sistema pronominal personal átono de tercera persona propio del castellano de la forma guaraní ichupe ${ }^{33}$, la cual, junto con su correspondiente plural ichupekuéra, funciona en guaraní paraguayo tanto en cuanto ob-

27 Véanse, en especial, los excelentes trabajos de Marcos A. Morfinigo, Hispanismos en el guarani, Buenos Aires, 1931; "Influencia del español en la estructura lingüística del guarani», en Filología, 5 (3), 1959, págs. 235-247; «Influencia del español sobre el léxico del guaraní, en la misma revista, 7, 1960, págs. 213-220; «Impacto del español sobre el guaraní», en Homenaje al Instituto de Filología y Literatura Hispanicas Dr. Amado Alonso, Buenos Aires, 1975, págs. 283-294.

28 Véase, respecto al fonetismo del castellano paraguayo, lo que digo en nota 16.

29 Pueden consultarse sobre este tema las páginas que le dedico, con perspectiva crítica, en mi reciente obra Estudios sobre un area dialectal hispanoamericana de población negra. Las tierras bajas occidentales de Colombia, Bogotá, 1977 y también JoRge A. SUAREZ, "Indigenismos e hispanismos vistos desde la Argentina", en Romance Philology, 20, 1966, págs. 68-90.

30 Según los datos del censo de 1962 referentes al total de la población de Paraguay, sólo un 4,4\% de la misma manejaba en dicho año exclusivamente el español mientras que un $45,1 \%$ era monolingüe guaraní y un $48,4 \%$ bilingüe español-guarant. Véase la $o b$. cit., en nota 26, págs. 19-32.

31 Cit. en nota 17.

32 Art. cit., págs. 52-53.

33 El grafema $\mathrm{CH}$ representa, en esta transcripción, la consonante guaraní fricativa prepalatal sorda. En otros sistemas de transcripción del guaraní se usa, para este sonido, el grafema $X$. 
jeto directo pronominal personal de tercera persona como en cuanto objeto indirecto del mismo paradigma ${ }^{34}$.

Para B. Usher de Herreros la invariabilidad en guaraní de ichupe / ichupekuéra respecto a la determinación pronominal personal del objeto directo y el objeto indirecto en la tercera persona ha podido determinar, por un proceso de interferencia, el empleo de la forma castellana le en ambos casos, de modo paralelo al guaraní, originándose así el actual leísmo que se constata en el español paraguayo.

A mi parecer, esta hipótesis, que la prematuramente desaparecida investigadora me confirmó oralmente, no puede ser aceptada como factor causal primario del estado de cosas que estudiamos y ello por varias razones, tanto internas, estructurales, como externas.

En primer lugar, la atribución primaria al influjo guaraní del leísmo paraguayo choca frontalmente con la existencia de otras áreas hispanoamericanas (Ecuador, zonas argentinas) en las que existe igualmente leísmo y en las que no es posible postular, de ningún modo, la presencia de guaranihablantes ni en la actualidad ni en ninguna otra época histórica. Es evidente que en estas áreas ( $y$ también en Paraguay, por lo tanto) han debido actuar otros factores causales en la producción del rasgo morfosintáctico que aquí nos ocupa aunque, como luego veremos con más precisión, ello no obsta para que, en el caso concreto del Paraguay, también haya tenido intervención en la formación del leísmo local la interferencia guaraní.

En segundo lugar, B. Usher de Herreros ${ }^{35}$ supone que la modalidad concreta del leísmo paraguayo deriva de un proceso evolutivo que ha llevado al complejo sistema pronominal personal átono de tercera persona propio del castellano a calcar el del guaraní, compuesto solamente de dos elementos morfológicos (el singular ichupe y el plural ichupekuéra) utilizados tanto para referirse a objeto directo como a directo $\mathbf{y}$ sin alteraciones formales debidas a categorías genéricas o lógico-semánticas. Esta apreciación no es, sin embargo, exacta y está basada en una descripción errónea de la realidad del leísmo paraguayo actual. En efecto, B. Usher de Herreros, quizá influida por la descripción que hace Ch. Kany de este fenómeno, cree que en Paraguay (al igual que en Ecuador) existen dos morfemas representativos del pronombre personal átono de tercera persona, le y les $\mathrm{y}$, basándose en este dato, desgraciadamente irreal, ha podido deducir que esta dualidad reproduce y se funda en la dualidad paralela existente en guaraní (ichupe-ichupekuéra). Hoy sabe-

34 Sobre el empleo en guaraní de ichupe / ichupekuéra véase P. ANTONio Guasch, El idioma guarani, Asunción, 1976, págs. 96-100.

35 Loc. cit., en nota 32. 
mos que esto no es así ya que, salvo en los casos derivados de la presión de la enseñanza escolar o del prestigio de las normas rioplatense general o peninsular europea, el leísmo del castellano paraguayo está expresado por un solo morfema pronominal personal átono (le), utilizado tanto para el singular como para el plural, con lo que, lógicamente, al dejar de producirse el paralelismo pretendido por B. Usher de Herreros entre los paradigmas del español paraguayo y del guaraní en este punto concreto, desaparece también la posibilidad de que haya sido la interferencia de la estructura pronominal personal del guaraní sobre la del castellano local la causante primaria del fenómeno que estudiamos.

Por otra parte, la estructura del guaraní clásico es de todo punto incapaz de proporcionar un criterio explicativo de la selección de la forma le en el castellano del Paraguay para reemplazar a las formas $l o, l a, l o s$, las, les que, existentes en el castellano peninsular europeo, se han desmorfologizado en su modalidad diatópica paraguaya. Creo que, tanto para fundamentar esta selección morfológica como para entender la totalidad del proceso de cambio verificado en el español del Paraguay, es preciso hacer intervenir otras causas genéticas.

Éstas son, en mi entender, las siguientes: la base dialectal peninsular europea del diasistema linguiístico paraguayo, la interferencia del guaraní paraguayo o jopará y no sólo del guaraní clásico ${ }^{36}$, la simplificación periférica, los resultados de la convivencia de sistemas lingüísticos en contacto y, finalmente, la actuación secular de tendencias internas dentro de las paradigmas estructurales morfosintácticos del castellano colonial de Hispanoamérica.

Considero que el factor causal primario, desencadenante del complejo conjunto de evoluciones posteriores que han desembocado finalmente en el leísmo paraguayo tal como hoy lo conocemos, puede ser identificado con la probable presencia en el español de los primeros núcleos europeos fundadores de agrupaciones urbanas dentro del territorio actualmente paraguayo ${ }^{37}$ de rasgos leístas similares a los que, en los si-

36 El concepto de guarani paraguayo como entidad lingüística perfectamente diferenciada, por una parte, del guaraní tribal actual y, por otra, del guaraní clásico o misionero e identificada con la modalidad popular de esta lengua hablada coloquialmente por la población mestiza, no tribal, del Paraguay se debe principalmente a LEÓN CADOgan. Véanse sus trabajos: «En torno a la enseñanza del guaraní y a su implantación como idioma oficial", en Ybyturuzú (Villarrica, Paraguay), 5, 1963, páginas 12-15 y 6, 1963, págs. 10-12; "Algo más sobre el guaraní paraguayo», en Alcor (Asunción), 44-45, 1967, págs. 3-6; "Datos para el estudio de algunas particularidades del guaraní familiar paraguayo», en Suplemento Antropológico. Universidad Católica (Asunción), 8 (1-2), 1974, págs. 15-49.

37 Sobre la conquista y colonización del Paraguay pueden verse Julio CÉSAR ChAves, Descubrimiento y conquista del Río de la Plata y el Paraguay, I, Asunción, 1968; 
glos XV y XVI, manifestaban en las áreas norteñas de las zonas castellanohablantes peninsulares.

Es sabido que, posiblemente ya desde el siglo XIr, a partir del empleo de formas le, li, les, lis para el objeto directo con verbos que en latín regían dativo para este uso, se va generalizando, en Castilla, León, Extremadura y Murcia principalmente, la utilización del pronombre personal le referido a objeto directo caracterizado por la nota ( + persona) o (en menos casos) ( + animado), llegándose a desarrollar, sobre todo en los estratos sociolingüísticos más populares ${ }^{38}$, tendencias evolutivas que tendían a la modificación del paradigma pronominal personal átono de tercera persona en cuanto al objeto directo, intentando llegar a una estructura trimembre caracterizada por el predominio de la diferenciación genérica (le m., la f., lo n.) sobre la casual ${ }^{39}$. Este proceso de cambio hacia $l e$, muy intenso en el masculino singular, menos en el femenino singular y muy escaso en el plural, parece haber sido predominantemente popular y limitado sobre todo a Castilla y León durante el siglo xv y primeros decenios del xVI, haberse extendido a todos los estratos sociales, incluso los más elevados, durante el resto del siglo XVI y XVII en toda la Península excepto Andalucía y Aragón y haber llegado a su culminación en el siglo XVIII ${ }^{40}$ para retroceder, desde entonces, aceleradamente hasta el momento actual ${ }^{41}$.

Sería, pues, perfectamente posible que los primeros conquistadores y colonizadores del área paraguaya hubiesen transportado consigo, dentro de los rasgos linguiísticos de su castellano originario, el empleo del leísmo, si bien no general y limitado por los condicionamientos funcionales antes mencionados ${ }^{42}$.

Sin embargo, para que esta hipótesis pueda ser asentada firmemente y considerada como realidad sólida es preciso, antes, confirmar históricamente que tanto las características regionales como sociales de los conquistadores y primeros pobladores del área paraguaya coinciden con las atribuibles a los núcleos humanos que, en la España europea, empleaban en su realización lingüística, en la primera mitad del siglo xvI, el rasgo

Efrafm Cardozo, El Paraguay colonial, Buenos Aires, 1957; Enrique de Gandfa, Indios y conquistadores en el Paraguay, Buenos Aires, 1932.

38 R. LAPESA, art. cit., en primer lugar en nota 7, págs. 534-535 y 550.

39 Véase el art. de R. LAPESA citado en la nota anterior, págs. 549-550 y también el trabajo de F. Marcos Marf́n cit. en nota 7, pág. 35.

40 Véase el trabajo de Rufino Josś Cuervo cit. en nota 5 y los artículos mencionados en la nota 7 .

41 Sobre este tema cfr. los datos que proporciona SaI.vador Fernández Ramfrez. en su obra citada en nota 6 .

42 Cfr. R. LAPESA, art. cit., en primer lugar en nota 7, págs. 531-541. 
morfosintáctico del leísmo. Felizmente, estamos en condición de afirmarlo así, fundamentando nuestra afirmación en datos comprobables históricamente.

Tanto en la expedición de don Pedro de Mendoza como en las posteriores acaudilladas por Cabeza de Vaca (1543), Diego de Sanabria (1547) y Ortiz de Zárate (1571), que constituyeron en conjunto la aportación humana básica de origen europeo a la población de la Gobernación del Paraguay durante los siglos XVI y XVII, sorprenden por su número y por la relevante personalidad de algunos de sus componentes los contingentes de conquistadores y primeros colonizadores de origen vasco y castellano norteño, en especial burgaleses. De esta última procedencia fueron, por ejemplo, Juan de Ayolas, Juan de Salazar y Espinosa, fundador de La Asunción, Juan de Garay, Diego de la Calzada, Diego Vecino, Gonzalo Casco y otras importantes figuras del Paraguay fundacional. Y, en términos estadísticos, los numerosos datos recopilados por Ricardo de Lafuente Machaín ${ }^{43}$ permiten, sin lugar a dudas, constatar que, entre los conquistadores y primeros pobladores del Paraguay, la superioridad numérica de castellanos viejos y vascos sobre andaluces y extremeños es indiscutible.

Por lo que se refiere a la determinación del estrato social al que pertenecían los núcleos europeos establecidos en el Paraguay durante el siglo XVI, basta consultar la mencionada obra de Lafuente Machaín para deducir que, a pesar de retóricas apelaciones a la nobleza de los primeros pobladores españoles de estos territorios ${ }^{44}$, siempre frecuentes en los memoriales y escritos oficiales dirigidos al Rey o al Consejo de Indias por sus descendientes, tienen razón Efraím Cardozo ${ }^{45}$ y J. Natalicio González ${ }^{46}$ cuando atribuyen a los fundadores europeos de las estirpes mestizas paraguayas una condición social media baja o decididamente humilde en cuanto a su procedencia, salvando algunas muy escasas excepciones.

Parece, pues, demostrado que, tanto por su procedencia geográfica como por el estrato socioeconómico al que pertenecieron en la Metrópoli, los pobladores españoles del Paraguay durante el siglo xvi pudieron poseer (y con probabilidad poseyeron) en su sistema lingüístico castellano, que trasplantaron consigo a sus nuevas comarcas de residencia, el

43 Conquistadores del Río de la Plata, Buenos Aires, 1937.

44 El gran gobernador del Paraguay Hernandarias de Saavedra, en memorial al Rey de 30 de enero de 1600 , dice, por ejemplo, que en la conquista de aquel territorio "se derramó la más ilustre sangre que de España ha pasado a las Indias» (Revista de la Biblioteca Nacional de Buenos Aires, I, 1937).

45 Ob. cit., en nota 37, págs. 55-56.

46 Proceso y formación de la cultura paraguaya, Buenos Aires, 1948. 
rasgo del leísmo pronominal, si bien limitado a los casos, relativamente restringidos, en que éste se manifestaba en sus comarcas de procedencia ${ }^{47} \mathrm{y}$, por lo tanto, muy distante de la modalidad paraguaya actual, de la que, no obstante, constituye, a mi parecer, su núcleo causal primario.

Podría, sin embargo, alegarse en contra de la afirmación anterior, al igual que se ha hecho ya en relación con algún otro problema del español de América más o menos semejante al que aquí abordamos ${ }^{48}$, que no es acertado postular la perduración indefinida de rasgos atribuibles solamente a una primera oleada de colonizadores en determinadas áreas hispanoamericanas que, a través del tiempo, han recibido nuevas aportaciones humanas, desde la Metrópoli o desde otras zonas geográficas continentales, las cuales habrían debido normalizar el uso linguístico de aquellas regiones y hacer desaparecer, por lo tanto, en las mismas los particularismos generados por sus primeros ocupantes. En el caso paraguayo que nos ocupa ( $y$ en otros) pienso que esta postura metodológica, originada en unas famosas páginas de Amado Alonso ${ }^{49}$, no es correcta por dos razones.

En primer lugar porque, como ha recordado luminosamente José Pedro Rona ${ }^{50}$, en las áreas de colonización los conquistadores y primeros pobladores imponen, durante el período temporal de su predominio (que puede ser muy corto), una norma linguística a la que tienden a acomodarse en circunstancias normales los contingentes posteriores de colonizadores. $Y$, en segundo, porque, en el caso concreto del Paraguay y por circunstancias socioeconómicas e históricas que posteriormente examinaré, se puede decir ${ }^{51}$ que la expedición de Juan Ortiz de Zárate de 1571 fue la última aportación importante de colonizadores españoles a la Provincia del Paraguay que va a tener lugar en casi dos siglos, ya que sólo en el último cuarto del siglo XviII vuelve de nuevo a apreciarse ${ }^{52}$ una significativa inmigración de contingentes humanos procedentes, esta vez,

47 Véase el trabajo citado en nota 7 en primer lugar, págs. 531-541.

48 Me refiero al tema tratado en mi trabajo Formas en -RE en el español atlántico y problemas conexos, ahora incluido en Estudios lingüísticos hispánicos, afrohispánicos y criollos, Madrid, 1978.

49 Recogidas ahora en el volumen Estudios lingüísticos. Temas hispanoamericanos, Madrid, 1953. Me refiero al trabajo titulado La base lingüistica del español americano (págs. 7-72 del volumen citado).

50 Aspectos metodológicos de la dialectología hispanoamericana, Montevideo, 1958.

51 Véase Efrafm Cardozo, ob. cit., en nota 37, págs. 56-57.

52 Deben consultarse sobre este tema los trabajos de Rafael Eladio Velázquez y E. Maeder. Véanse, sobre todo, R. E. Vel.Azouez, "La población del Paraguay en 1682», en Revista Paraguaya de Sociología, 9 (24), 1972, págs. 128-148 y E. MAEDER, aLa población del Paraguay en 1799. El censo del Gobernador Lázaro de Rivera», en Estudios Paraguayos, 3 (1), 1975.

LXII, 3.0-4.0 - 6 
principalmente del área sureña rioplatense. Por todo ello pienso que es lícito postular, en cuanto al fenómeno específico que ahora tratamos, su persistencia desde el siglo Xvi en el territorio paraguayo con las modalidades funcionales dichas, como consecuencia de las características diatópicas diastráticas y temporales del habla de sus conquistadores y primeros pobladores y, en este sentido, la consideración de este hecho como elemento causal primario en el complejo entramado de factores que, en su interacción, han llevado a la situación actual del yeísmo paraguayo.

Una vez sentado este punto y determinado cuál pudo ser la característica de la base lingüística del español paraguayo en el siglo xvr que sirvió de foco difusor al leísmo que actualmente constatamos en este territorio nos resta intentar explicar cómo y en virtud de qué factores sociohistóricos y linguísticos este rasgo, originalmente reducido con toda probabilidad (como en las áreas castellanas de la Metrópoli) a su uso con relación a objeto directo en singular masculino y sólo en casos poco frecuentes en singular femenino y en plural ${ }^{53}$, pudo generalizarse en castellano paraguayo también con referencia a estos dos últimos tipos de antece. dente y, al mismo tiempo, dar lugar a un paradigma pronominal personal átono de tercera persona constituido por el único e invariable morfema le.

Creo, como apunté anteriormente, que en la realización de estos procesos evolutivos actuaron varios factores determinantes que, si bien coincidieron en gran parte en cuanto a sus efectos y en cuanto a sus líneas y modalidades concretas de influencia, conviene analizar independientemente desde el punto de vista conceptual.

El primero de ellos podría ser identificable con el denominado por B. Malmberg simplificación periférica ${ }^{54}$.

Es sabido que, como consecuencia de peculiares circunstancias socioeconómicas y geográficas, determinadas áreas territoriales pueden quedar marginadas de la actuación normativa procedente de los centros de cultura existentes en un momento dado y que, en esos casos, la relajación o ausencia de los modelos de prestigio linguístico propuestos por la o las áreas centrales puede producir, al mismo tiempo que fenómenos de conservación o arcaísmo, casos de fuerte innovación antitradicional $e$, incluso, revolucionaria, dirigida, en muchas ocasiones, a la realización de estructuras lingüísticas intensamente simplificadas respecto a las originalmente recibidas desde la o las metrópolis culturales ${ }^{55}$. Este enfoque

53 R. LAPESA, art. cit., en nota 7 en primer lugar, págs. 549-551.

54 Véase, sobre todo, B. Malmberg, "L'extension du castillan et le problème des substrats», en Actes du Colloque International de Civilisations, Littératures et Lan. gues Romanes, Bucarest, 1959, págs. 249-259.

55 Sobre la coexistencia de fenómenos de arcaísmo e innovación en áreas laterales 
es, sobre todo, especialmente útil en los estudios acerca de áreas de colonización linguiística en las que, por su misma naturaleza, es muy frecuente la existencia de zonas periféricas a las que pueden aplicarse, con resultados generalmente fértiles, los conceptos metodológicos aquí ligeramente esbozados ${ }^{56}$.

Parece indudable, a la luz de los criterios fijados por la nueva historia social de Hispanoamérica ${ }^{57}$, que el Paraguay entra de lleno, al menos durante el lapso de tiempo comprendido entre los siglos XVI-XVIII y probablemente también en lo que se refiere a las siete primeras décadas del siglo XIX, dentro de la categoría de área periférica respecto al resto del área sudamericana y ello en virtud de cuatro condicionamientos socioeconómicos: su pobreza económica, su aislamiento geográfico, su bajo nivel cultural y educativo y su peculiar condición fronteriza con el corolario forzoso de una también peculiar forma de existencia colectiva ${ }^{58}$.

Desde el punto de vista económico, la suerte del Paraguay quedó decidida por varios siglos cuando, tras las frustradas expediciones de Ayolas, Cabeza de Vaca y Nuflo de Chaves, la Corona se convenció de que en el territorio paraguayo, lejos de existir la Tierra Rica o la Sierra de la Plata de que hablaban las leyendas aborígenes, no existían ni minas de metales preciosos ni yacimientos de piedras de valor. Abandonados prácticamente por la Metrópoli, prácticamente incomunicados con el Alto Perú (de cuya Audiencia de Charcas dependían, sin embargo) por las interminables extensiones chaqueñas, muy distantes de la costa atlántica

(o periféricas) véanse IORGU IORDAN, «Le roumain et l'espagnol, aires latérales de la Romania", en Revue Roumaine de Linguistique, 9 (1), 1964, págs. 5-14 y Marius SalA, «El rumano y el español, áreas laterales de la Romania», en Lengua - Literatura-Folklore. Estudios dedicados a Rodolfo Oroz, Santiago, 1967, págs. 439-447. Sobre los procesos de simplificación y los «sistemas mínimos» véase B. MalMBerg, «Minimal systems, potential distinctions and primitive structures", en Acts of the Vth. International Congress of Linguists, Cambridge, 1962, págs. 78-83.

$56 \mathrm{He}$ empleado en varias ocasiones métodos de análisis basados en los conceptos aquí mencionados para estudiar diferentes problemas del español americano. Véanse mis libros Estudios sobre un área dialectal hispanoamericana de población negra. Las tierras bajas occidentales de Colombia, Bogotá, 1977 y Estudios lingüisticos hispánicos, afrohispánicos y criollos, Madrid, 1978.

57 Cfr. Richard Graham y Peter H. Smith (eds.), New Approaches to Latin American History, Austin, 1974; JAMES LockHART, "The social history of colonial Spanish America: evolution and potential», en Latin American Research Review, 7 (1), 1972 , págs. 6-45. Un excelente ejemplo de la aplicación de estos nuevos criterios metodologicos es Murdo J. Mac Leod, Spanish Central America: a Socio-economic History, 1520-1720, Berkeley, 1973.

58 Para una visión general de las peculiaridades históricas del Paraguay pueden consultarse J. Natalicio Gonzalez, Proceso y formación de la cultura paraguaya, I, Buenos Aires, 1938; Efrafm Cardozo, El Paraguay colonial, Buenos Aires, 1959; Justo Pastor Benttez, Formación social del pueblo paraguayo, Asunción, 1955. 
y de sus puertos, los pobladores del Paraguay debieron limitarse a desarrollar una agricultura de mera subsistencia (sólo alterada en el siglo XVII por la explotación de la yerba mate) y una ganadería escasamente productiva lo que, sumado a la perpetua situación de guarnición fronteriza siempre amenazada por los insumisos indios chaqueños por el Oeste y por las incursiones de las «bandeiras» portuguesas por el Este, produjo, como era lógico, una situación realmente aflictiva de pobreza general.

Así lo testimonian no solamente detalles altamente significativos como la no utilización de moneda metálica en el Paraguay hasta muy entrado el siglo XVIII ${ }^{59}$, el carácter extremadamente humilde, casi elemental, de las viviendas de Asunción y el resto de la Provincia hasta las mismas fechas ${ }^{60}$, la rareza y aprecio en que se tenían los más comunes objetos procedentes de la lejanísima metrópoli ${ }^{61}$, etc., sino también las múltiples manifestaciones de esta desoladora situación que han llegado hasta nosotros en documentos de la época. Así, en 1597 Baltasar Ramírez ${ }^{62}$ escribe "Toda aquella tierra [Paraguay] es muy pobre porque no tiene oro ni plata y las cosas que produce la tierra no tienen valor ni estima», opinión a la que se suma en 1600 el Obispo de Tucumán quien expresa que «no tiene sustancia la tierra para comprar las cosas que del Perú vienen por ser de partes tan longinquas, y más essa pobre tierra del Paraguay " ${ }^{3}$. Finalmente el Procurador de la ciudad de La Asunción escribe en 1605 que «Es tanta la pobreza que hoy tienen los vecinos y moradores de dicha mi parte que si se caen sus casas no las pueden alsar y remediar ni tienen posible para ello» ${ }^{64}$.

Bien es verdad que, hacia fines del siglo XVIII, tras la apertura oficial al tráfico marítimo del puerto de Buenos Aires, la diversificación de cultivos (tabaco, algodón, caña) y la desaparición de la competencia que, para la yerba mate cultivada en la Provincia por particulares, representaba la producida en las misiones jesuíticas, mejoró claramente la situación económica del Paraguay ${ }^{65}$ pero ni en este período final de soberanía

59 Cfr. Efraím Cardozo, Las primeras monedas en el Paraguay, en Actas del II Congreso Internacional de Historia de América, t. V, Buenos Aires, 1938, págs. $490-551$.

60 Véase RAMÓN GUTIÉRREz, Evolución urbanistica y arquitectónica del Paraguay, 1537-1911, Resistencia (República Argentina), 1976.

61 Recoge numerosos testimonios de este hecho J. Natalicio González en su obra citada en nota 58.

62 Descripción del Reyno del Perú, cit. por EnRIoue DE Gandta, en Indios y Conquistadores del Paraguay, Buenos Aires, 1932, pág. 68.

63 Carta de 2 de mayo de 1600, A. G. I. 74-6.21.0, cit. por Efrafm Cardozo, ob. cit., en nota 58, pág. 91.

64 Doc. cit. en Efrafm Cardozo, ob. cit., en nota 58, pág. 91.

65 Véase Rafael. Eladio Velazouez, El Paraguay en 1811, Asunción, 1966. 
española ni durante la época del Doctor Francia, a pesar de la meritoria labor del Supremo Dictador en la redistribución de los recursos del país mediante un régimen económico identificable con un peculiar «socialismo de Estado" ${ }^{66}$, consigue el Paraguay superar su situación de extremo subdesarrollo. Solamente la breve etapa de gobierno de Carlos Antonio López y de su hijo, el Mariscal Francisco Solano López ${ }^{67}$, puede ser considerada como excepcional en cuanto a la dinamización de la vida económica del país mediante el incremento del comercio exterior, la creación de una industria autónoma (fundición de Ybycuí, por ejemplo) y el desarrollo de las vías de comunicación externas (flota mercante del Estado) e internas (ferrocarril, telégrafo) pero, desgraciadamente, la Guerra Grande de 1865 a 1870 frustró este prometedor camino y volvió a sumir en la pobreza, agravada, además, por una antinacional política de enajenación de recursos a favor de empresas o particulares extranjeros ${ }^{68}$, a la heroica y desgraciada nación paraguaya.

A la pobreza del Paraguay durante el período colonial y buena parte de su etapa independiente hay que añadir, como un factor más, determinador de su carácter periférico, su aislamiento y relegación. Entre los condicionamientos generadores de esta situación figuran, naturalmente, en primera fila su situación geográfica desfavorable, en el corazón de la América del Sur y separada por distancias enormes de los puertos de Lima y Buenos Aires, y su mismo estado de abandono y subdesarrollo económico pero también, al mismo tiempo, otros factores, extraordinariamente negativos, de índole política, económica y social. Entre ellos son quizá los más importantes la amputación del Paraguay de la comarca del Guairá histórico, ribereña del Atlántico, por los «bandeirantes» portugueses ${ }^{69}$, la división de la Provincia del Paraguay en 1616 con la segre-

66 Cfr., para la biografía del Doctor Francia y su obra de gobierno, Julio César Chaves, El Supremo Dictador, Madrid, 1964 y, para su política económica y social, el acertado e iluminador trabajo de RichaRd ALAN WhITE, «La política económica del Paraguay popular (1810-1840). La primera revolución radical de América», en Estudios Paraguayos, 3 (1) y 3 (2), 1975, y 4 (1), 1976.

67 Sobre la figura y la obra de Carlos Antonio López pueden consultarse Julio César Chaves, El Presidente López, vida y gobierno de Don Carlos, Buenos Aires, 1968 y Juan F. Pérez Acosta, Carlos Antonio López, Obrero Máximo, Buenos Aires, 1948. Sobre la gran figura del Mariscal López debe verse aún el ya viejo libro de Juan E. O'Leary, El Mariscal Solano Lopez, Asunción, 19703.

68 Para el período posterior a 1870 en el Paraguay y su peculiaridad socioeconómica puede verse Carios PAstore, La lucha por la tierra en el Paraguay, Montevideo, 1972, representante de una interpretación partidista (liberal) en relación con el tema pero con abundancia de datos. También Francisco Gaona, Introducción a la historia gremial y social del Paraguay, Asunción, 1967.

69 Cfr. Ramón I. Cardozo, La antigua provincia del Guairá y Villa Rica del Espíritu Santo, Buenos Aires, 1938; Basilio MagalhaES, Expansão geográfica do Brasil colonial, 
gación de la misma de Buenos Aires y sus inmensas dependencias ${ }^{70}$, el perpetuo estado de guerra mantenido contra los moradores mestizos del Paraguay por los indios chaqueños y los mbayá y payaguá del territorio al oriente del río ${ }^{71}$, las malocas continuas de los mercaderes de esclavos del sur brasileño ${ }^{72} \mathrm{y}$, en fin, las trabas administrativas y económicas, realmente abrumadoras, impuestas por las autoridades metropolitanas y virreinales a la navegación y el comercio paraguayos por el Río de la Plata ${ }^{73}$, con la creación del "puerto preciso» de Santa Fe ${ }^{74}$. Esta situación, de virtual y casi completo enclaustramiento, afectó al Paraguay hasta el tercer cuarto del siglo xviII y prosiguió aún, tras unos pocos decenios de relajamiento, desde 1814 hasta 1840, época en que el Dr. Francia impuso al país un aislamiento aún más completo (exceptuando el escaso comercio realizado por el puerto fluvial de Itapúa con traficantes brasileños) el cual determinó su justificada consideración, en este período de tiempo, como «el Tibet de América» ${ }^{75}$.

Juntamente con la pobreza y el aislamiento, otra importante característica sociológica aplicable a la población del Paraguay contribuye notablemente a su condición marginal dentro de la América del Sur. Me refiero a su peculiar forma de vida, derivada de los condicionamientos históricos que, desde el siglo XVI hasta el XIX, han hecho de esta región una verdadera marca fronteriza y de sus habitantes, casi sin excepción, un notable grupo de campesinos-soldados. Es muy justa la caracterización de Juan Francisco Aguirre, expresada en el siglo xvirl en estas palabras:

São Paulo, 1935; Bandeirantes no Paraguai. Documentos inéditos do século XVI, São Paulo, 1949; Jesuitas e bandeirantes no Guairá (1549-1640), Río de Janeiro, 1951; Francisco de Solano, Contactos hispanoportugueses en América a lo largo de la frontera (1500-1800), en Primer Coloquio Luso-Español de Historia de Ultramar, Valladolid, 1973 (separata).

70 Cfr. Rafael Eladio Velazouez, La población del Paraguay en 1682, Asunción, 1972 y las obras citadas en nota 58.

71 Véase Branislava SUSNIK, «Dimensiones migratorias y pautas culturales de los pueblos del Gran Chaco y de su periferia (enfoque etnológico)», en Suplemento Antropológico. Universidad Católica, 7 (1-2), 1972, págs. 86-105. También MANURL Domf́NGUEZ, Expediciones del Paraguay al Chaco, Asunción, 1934.

72 Véase la bibliografía citada en nota 69 y añádase, para los territorios norteños del Paraguay, Thierry Saignes, «L'indien, le portugais et le jésuite. Alliances et rivalités aux confins du Chaco au XVIIIe siècle», en Cahiers des Amériques Latines, 9-10, 1974, págs. 213-245.

73 Cfr. Rafael Eladio Velazouez, «Navegación entre el Paraguay y el Río de la Plata», en III Congreso Hispano-Americano de Historia, Cartagena, 1961 (ponencia ciclostilada) y «Navegación paraguaya de los siglos XVII y XVIU», en Estudios Paraguayos, 1, 1973 (cito por separata).

74 Cfr. Fulgencio R. Moreno, Estudio sobre la independencia del Paraguay, Asunción, 1911.

75 Véanse los testimonios contemporáneos recopilados por F. PÉrEz MARICEVICH y ARturo Nagy, en su obra Paraguay. Imagen romántica, Asunción, 1969. 
«El glorioso título de militar conviene a la Provincia del Paraguay. Desde su fundación hasta ahora ha estado con las armas en las manos, con más o menos fatiga y mayores o menores enemigos ${ }^{76}$. En efecto, frente a los guaicurúes chaqueños, los payaguás y mbayás como frente a los mamelucos portugueses, combatiendo como voluntarios en Buenos Aires y Montevideo a los invasores ingleses, peleando en guerras intestinas como las mantenidas con las tropas de guaraníes acaudilladas por jesuitas durante la rebelión comunera o enfrentándose heroicamente con las fuerzas de la Triple Alianza hasta la hecatombe trágica de Cerro Corá, la historia paraguaya, durante más de tres siglos, es la de un pueblo que ha ejercitado, simultáneamente y sin respiro, la espada o el arma de fuego junto con la herramienta del agricultor, sin poder casi, desgraciadamente, atender a otra ocupación. Así, en 1748, el Cabildo de Asunción en comunicación al Rey describe de este modo la vida de los moradores del Paraguay: "en cada un mes montan la guardia una semana y vuelve el retorno (que es una compañía) de manera que no tienen más de tres semanas y de éstas las ocupan las dos para sus labranzas y cultivo de la tierra para el sustento y mantenimiento de sus mugeres e hijos y la otra para prevenirse de peltrechos de armas, pólvora y munición, caballos y vituallas para volver a montar la guardia y servicio de su semana en el Presidio que les toca» ${ }^{77} \mathrm{y}$, en 1798, el Gobernador Lázaro de Ribera se dirige al Virrey Feliú expresándole que "desde que se conquistó esta tierra [el Paraguay] hasta el día han estado y están todos los vecinos constituidos en la obligación de defender la Provincia a su costa, con caballos y municiones, representándose como un cuerpo que debe estar pronto para contener la invasión y crueles sorpresas de los indios que la hostilizan sin cesar" ${ }^{78}$. Es perfectamente lógico que esta clase de vida en la que, como afirmaban orgullosamente, dirigiéndose al Rey, los fundadores paraguayos de Vera de las Siete Corrientes, "el mayor ejercicio que en estas tierras tenemos son las armas y las conquistas» ${ }^{79}$, haya podido producir un tipo humano colectivo, heroico y guerrero, muy diferente al de otras zonas, más pacíficas, de la América española y caracterizado por los rasgos inconfundibles del hombre fronterizo.

76 «Diario del Capitán de Fragata D. Juan Francisco Aguirre» (2.^ parte), en Revista de la Biblioteca Nacional de Buenos Aires, 1950, pág. 299.

77 Archivo Nacional de Asunción, Sección Historia, volumen 50, documento n.o 2.

78 Comunicación de 4 de diciembre de 1789 cit. por E. Cardozo, El Paraguay colonial, Buenos Aires, 1959, pág. 221.

79 Carta de la ciudad de Vera [hoy Corrientes] al Rey de 5 de abril de 1588, en Colección de Copias del Archivo de Indias de la Biblioteca Nacional de Buenos Aires, n. 815. 
Es, asimismo, congruente con los datos que hasta aquí hemos expuesto que una comarca como el Paraguay, prácticamente aislada, en perpetuo pie de guerra, de economía pobre y reducida, durante casi tres siglos, a mantener una conducta vital en que la subsistencia física era preocupación apremiante, haya evidenciado, casi hasta el siglo $\mathrm{xx}$, un nivel cultural extraordinariamente bajo.

Ya a fines del siglo Xvi el Gobernador Hernandarias de Saavedra se dirige al Provincial de los jesuitas, P. Diego de Torres Bollo, en términos dramáticos, pidiéndole "se sirva condolerse de estos pobres muchachos hijos de españoles que han perdido sin saber hablar ni las demás cosas que se deben saber de policía y doctrina como hijos de españoles, de todo lo cual carecen" ${ }^{80}$. La educación suministrada en el Paraguay, limitada al nivel primario y a las escasas enseñanzas suministradas en las poco abundantes casas religiosas de la Provincia, parece haber sido de calidad muy mediocre sobre poco amplia en cuanto a su radio de influencia ${ }^{81}$ por lo que, a pesar de la excelente labor realizada en Asunción por los jesuitas y de los buenos deseos del Cabildo de la ciudad y de los Gobernadores ${ }^{82}$, el estado educativo de la Provincia debió dejar mucho que desear, hasta el extremo de que, en 1625 y en 1753 por ejemplo, el Cabildo de Asunción tuvo que dirigirse al Rey exponiendo el peligro de que los hijos de los conquistadores adquirieran las costumbres de los indios y solicitando, en vano, la fundación de un colegio en la capital de la Provincia ${ }^{83}$. Es muy significativo, por otra parte, que el Cabildo Catedral informara oficialmente, en 1650, que los sacerdotes ordenados por el Obispo Cárdenas eran «tales que apenas saben leer» ${ }^{84}$, lamentación que repite, en 1678, el Obispo Casas quien dice que «de mis clérigos raro es el que sabe gramática y muchos los que ni leer saben» ${ }^{85}$.

En cuanto a la enseñanza superior, tanto la pobreza general de la Provincia como la gran distancia que separaba a Asunción de las localidades de Córdoba y Chuquisaca, sedes de las Universidades más cercanas, impedían prácticamente el acceso de los moradores del Paraguay a los grados universitarios ${ }^{86}$ como lo comprueba el hecho de que, aún en

\footnotetext{
80 Cit. por Raúl A. Molina, Hernandarias, el hijo de la tierra, Buenos Aires, 1949, pág. 300.

81 Véase Olinda Massare de Kostianowsky, La instrucción pública en la época colonial, Asunción, 1975.

82 Rafael Eladio Velazouez, La educación paraguaya en el siglo XVIII, en Historia Paraguaya, 1966.

83 Cfr. Rafael Eladio Veldzouzz, El Paraguay en 1811, Asunción, 1966, págs. 88-89.

84 Cit. por R. E. Velázquez en art. cit. en nota 82, pág. 125.

85 Cit. por R. E. Velázquez en art. cit. en nota 82, pág. 126.

86 En 5 de julio de 1715 el Alférez Real de Asunción, D. Dionisio de Otazú, se dirige al Gobernador expresando que "consta al celo de Vuestra Merced el descon-
} 
1700, únicamente tres paraguayos poseyeran el título de Doctor ${ }^{87}$. Sólo en 1783, en virtud de Reales Cédulas de 1776, 1779 y 1780, se inauguró en Asunción el Real Colegio Seminario de San Carlos, de gran utilidad para la formación de la juventud paraguaya hasta que fue suprimido, en 1822, por órdenes del Doctor Francia ${ }^{88}$, con lo que, hasta la etapa de gobierno de Carlos Antonio López, el Paraguay careció de nuevo de centros de enseñanza media y superior ${ }^{89}$.

Creo que a la vista de los datos recogidos en las páginas anteriores, que configuran, sin lugar a dudas, a la sociedad paraguaya, desde el siglo XVI al XIX, como caracterizada por la pobreza general, el abandono por parte de la metrópoli europea y de los núcleos urbanos directivos de la América española, el aislamiento, el estilo de vida campesino-militar propio de una comarca de frontera y el bajo nivel cultural, es lícito deducir que debe ser incluido el Paraguay, durante la mayor parte de su trayectoria temporal, dentro de la categoría histórico-cultural (y también lingüística, por lo tanto) de área periférica.

Partiendo de esta conceptuación estimo que adquiere su verdadero sentido el proceso morfosintáctico que estudiamos en relación con la modalidad leísta del Paraguay. En efecto, si, como admiten los especialistas que han trabajado sobre este tipo de problemas, es normal que se den simultáneamente en las zonas linguiísticas periféricas tanto fenómenos de arcaísmo pasivo como otros, polarmente opuestos, de innovación extrema, propiciados ambos por la escasa o inexistente presión de la norma emanada de los centros lingüísticos prestigiosos, cabe identificar la evolución diacrónica que ha tenido lugar en el Paraguay respecto a los pronombres personales átonos de tercera persona con un intento, plenamente conseguido, de lograr una simplificación estructural máxima en este punto del sistema morfológico español en el que, por razones que encuentran su fundamento en la peculiar evolución del paradigma pronominal personal latino en nuestra lengua, se había producido un verda-

suelo y clamor universal de los vecinos de esta Provincia de no poder conseguir el dar estudio a sus hijos por la distancia de más de 300 leguas que hay de esta ciudad a la de Córdoba donde hay Universidad y que así por la pobreza general de dichos vecinos como por no correr moneda de plata en esta provincia son muy pocos y muy raros los que pueden costear a sus hijos en dicha Universidad» (Archivo Nacional de Asunción, Sección Historia, volumen 87, n. ${ }^{\circ}$ ).

87 Los hermanos José Bernardino y José Servín, sacerdotes, doctores por la Universidad de Córdoba, y José Dávalos y Peralta, doctor y catedrático de la Universidad de San Marcos de Lima.

88 Rafael Eladio Vel.Azouez, ob. cit., en nota 83, págs. 89-91.

89 Para las instituciones educativas en este período, en las que desempeño un importante papel el español Ildefonso A. Bermejo, véase R. E. Vel.Azourz, Breve historia de la cultura en el Paraguay, Asunción, 1966. 
dero punto crítico, abocado a reestructuraciones, más o menos intensas, durante toda la historia del castellano de las que son manifestaciones significativas los fenómenos del leísmo, loísmo y laísmo ${ }^{90}$.

Así pues, en el Paraguay lo que parece haber ocurrido, respecto al tema que nos ocupa, ha sido el desarrollo, llevado a sus más extremas consecuencias, de la tendencia reestructuradora de un esquema morfológico excesivamente complejo y parcialmente inadecuado para las necesidades comunicativas de los hablantes ${ }^{91}$, tendencia que, ya existente dentro del sistema castellano ${ }^{92}$, se radicalizó extremadamente en el área periférica paraguaya desembocando, al fin, en la eliminación de la totalidad de los morfemas empleados para significar las funciones pronominales personales objeto de tercera persona salvo le y ampliándose este último en cuanto a su uso para comprender los diferentes ámbitos de aplicación de los otros elementos desmorfologizados además del propio. De este modo se da paso en el Paraguay a un "sistema mínimo" en cuanto a los pronombres personales átonos de tercera persona, mediante la eliminación de distinciones consideradas como "potenciales» por el hablante ${ }^{93}$, con el cual, y sin perjuicio de la comunicación mínima exigible, se simplifica un paradigma originario excesivamente recargado y se adecua el mismo a las necesidades expresivas, reducidas a la dimensión más restringida, de una sociedad periférica como la paraguaya, sin perder de vista, además, que para la realización de este cambio simplificador, impulsado en cuanto a su proceso genético por las circunstancias socioculturales ya mencionadas y en cuanto a su origen causal ${ }^{94}$ por la inadecuación y complejidad del sistema pronominal castellano, los moradores del Paraguay no hacían sino prolongar, hasta su más extremo desarrollo,

90 Véanse las agudas observaciones de R. Lapesa y F. Marcos Marín respecto a este tema en sus arts. cits. en nota 7.

91 Me refiero, en especial, a la pervivencia parcial del paradigma casual latino del pronombre personal, hecho que, careciendo de motivación sincrónica clara para el hablante castellano, impide, además, la expresión más intensa de las oposiciones genéricas y semánticas, fuertemente marcadas en la lengua española. Véanse sobre todo ello los arts. mencionados en la nota anterior.

92 Sobre el concepto de tendencia lingüística véanse A. GraUR, Tendinţele actuale ale limbii române, Bucarest, 1968 y M. SALA, «Sur la tendance linguistique», en Revue Roumaine de Linguistique, 10 (5), 1970, págs. 507-509 y Contributions d la phonétique historique du roumain, Paris, 1976.

93 Cfr., para el valor de estos conceptos, el trabajo de B. Malmberg cit. en nota 55 .

94 Empleo aquí los conceptos teóricos ya utilizados por mí en el trabajo titulado La velarización de $/ \vec{R} /$ en el español de Puerto Rico, incluido ahora en Estudios linguiisticos hispánicos, afrohispánicos y criollos, Madrid, 1978, págs. 11-79. Véase también el excelente planteamiento del tema en J. VACHEK, «On the interplay of external and internal factors in the development of language», en Lingua, 1962, págs. 433-448. 
las posibilidades indicadas por el leísmo de tipo castellano que, como expuse antes, ya muy posiblemente poseían en su modalidad lingüística los conquistadores y primeros pobladores del país.

Por otra parte, debemos considerar también como elemento coadyuvante de gran importancia al proceso de cambio aquí estudiado el condicionante representado por la interferencia de sistemas. Es sabido que este factor causal ha sido valorado, con práctica unanimidad, como muy activo en cuanto a la producción de fenómenos de simplificación en las estructuras linguísticas en contacto como puede comprobarse, en el dominio románico general, respecto a evoluciones tan importantes como las relacionadas con la reestructuración del sistema latino de vocalismo ${ }^{95} \mathrm{o}$ la palatalización ${ }^{96} \mathrm{o}$, en el ámbito de la Romania Nueva, respecto a notables cambios lingüísticos experimentados en el portugués del Brasil. El carácter general de estas tendencias simplificadoras producidas por el contacto y convivencia de lenguas y la extensión e intensidad de sus resultados son aspectos que pueden recibir también confirmación en estudios realizados sobre sistemas linguiísticos muy alejados de la familia románica e, incluso, indoeuropea como puede verse, por ejemplo, en la brillante investigación realizada por Jean Caudmont sobre un dialecto septentrional del quéchua ${ }^{97}$.

No cabe duda alguna de que el Paraguay ha permanecido, continua y permanentemente, en una situación lingüística en la que las dos lenguas mayoritarias, español y guaraní, han estado en contacto estrecho e íntimo, al menos en la sección oriental del país, al este del río Paraguay ${ }^{98}$, prácticamente desde el inicio de la colonización española hasta la actualidad ${ }^{99}$. Así lo manifiestan gran número de testimonios históricos de entre los cuales seleccionamos, por su carácter explícito y su valor documental, solamente unos pocos, representativos, no obstante, de otros muchos escalonados entre los siglos XVI y XIX.

Hacia 1758 el P. José Cardiel se expresa del siguiente modo:

95 Véase sobre este tema, en lo que se refiere a la Península Ibérica, el conocido trabajo de Emilio Alarcos, "Quelques précisions sur la diphtongaison espagnole», en Omagiu lui Iorgu Iordan, Bucarest, 1958, págs. 1-4.

\% Cfr. A. NandRIş, Les palatalisations romanes, en Orbis, 1, 1952, págs. 136-145.

97 «a influencia del bilingüismo como factor de transformación en un sistema fonológico», en Revista Colombiana de Antropología, 2 (2), 1954, págs. 209-218.

98 La sección occidental del Paraguay actual, el Chaco paraguayo, sobre estar poblado, aún hoy, por etnias de lengua mayoritariamente no guaraní, permaneció prácticamente insumiso a las autoridades españolas y republicanas hasta muy entrado el siglo XIX.

99 En el Censo de 1962 solamente un 6,5 \% de la población aparece como no conocedora del guaraní mientras que los hablantes del castellano representan un $52,8 \%$. 
El lenguaje o jerigonza que a los principios sabían no es otra cosa que un agregado de solecismos y barbarismos de la lengua guaraní y guaraní y castellano, como se usa en toda la Gobernación del Paraguay y en la jurisdicción de Corrientes. En una y otra ciudad los más saben castellano pero en las villas y en todas las poblaciones del campo, chacras y estancias no se habla ni se sabe por lo común, especialmente entre las mujeres, más que esta lengua tan corrupta 100.

Por su parte, el P. José Manuel Peramás, jesuita de los expulsados en 1768, añade que:

El idioma guaraní se emplea corrientemente entre los españoles de la ciudad de Corrientes, lo mismo que en las colonias de Villa Rica y Curuguaty. Es más, en la misma ciudad de Asunción el P. Roque de Rivas explicaba en guaraní, desde el púlpito, los misterios de la religión y los deberes morales con gran aplauso y provecho de sus oyentes, los cuales, aunque hablan el español, prefieren se les hable en guaraní, al que están acostumbrados desde niños y en el que conversan entre sí, en el campo y en sus casas 101 .

\section{Añadamos a estos testimonios el del P. Martín Dobrizhoffer quien hace constar que:}

Todo el vulgo, aun las mujeres de rango, niños y niñas, hablan el guaraní como su lengua natal, aunque los más hablen bastante bien el español. A decir verdad, mezclan ambas lenguas y no entienden bien ninguna. Pues después que los primeros españoles se apoderaron de esta provincia, que antes estaba habitada por los carios o guaraníes, tomaron en matrimonio las hijas de los habitantes por falta de niñas españolas y por el trato diario los maridos aprendieron el idioma de las esposas y, viceversa, las esposas el de los maridos pero, como suele ocurrir generalmente cuando, aun en la vejez, se aprenden idiomas, los españoles corrompían miserablemente la lengua india y las indias la española 102.

Terminaré esta relación con un párrafo de Félix de Azara, quien afirma lo que sigue:

La diferencia en el origen de los españoles... ha producido otra en los idiomas de los Gobiernos de Buenos Aires y Paraguay, porque en aquél sólo se habla castellano y en éste sólo el guaraní, sucediendo esto mismo en la ciudad de Corrientes por su inmediación al Paraguay; sólo los más cultos entienden y hablan el español ${ }^{103}$.

100 José Cardiel, Declaración de la verdad, Buenos Aires, 1900, págs. 392-393.

101 José Manuel Peramas, La República de Platón y los guaranies, Buenos Aires, 1946, pág. 74.

102 Martf Dobrizhoffer, Historia de los Abipones, I, Resistencia (República Argentina), 1967, págs. 149-150.

103 Félix de Azara, Descripción e historia del Paraguay y del Río de la Plata, Madrid, 1847, pág. 298. 
Del mismo modo que la interferencia del sistema lingüístico español sobre el guaraní produjo el actual guaraní paraguayo, tan fuertemente simplificado y reestructurado ${ }^{104}$ que B. Meliá ha podido denominarlo (con términos cuyas implicaciones teóricas no comparto) "tercera lengua del Paraguay» en relación con el guaraní tribal o clásico y el castellano regional normativo ${ }^{105}$, pienso que, por un proceso paralelo y aún poco estudiado, el castellano del Paraguay ha podido, por la interferencia, general y permanente, del guaraní, además de admitir numerosos préstamos léxicos y morfológicos y de producir abundantes calcos morfosintácticos derivados de modelos guaraníes, simplificar algunos de sus paradigmas gramaticales en forma análoga a la que, en circunstancias equivalentes, ha tenido lugar, por ejemplo, en áreas del judeoespañol en algunos aspectos fonológicos y morfológicos ${ }^{106}$. Este proceso es doblemente posible en aquellos casos en los que (como en el que nos interesa) se dan simultáneamente dos condicionamientos favorables: un paradigma castellano en situación crítica (por su complejidad o inadaptación funcional) que ha manifestado ya anteriormente tendencias reestructuradoras y un sistema más simple o mejor adaptado a unos condicionamientos comunicativos concretos en la lengua interferente, el guaraní en este caso ${ }^{107}$. Téngase presente, en relación con este punto, que la tesis aquí mantenida no es coincidente con la que sustenta B. Usher de Herreros ${ }^{108}$ ya que la investigadora paraguaya atribuye el leísmo en el español de su país a un calco del paradigma pronominal personal de tercera persona del guaraní mientras que, por el contrario, mi propia posición está fundamentada sobre un proceso general (no específico) de simplificación derivado de condicionamientos atribuibles a la totalidad de los sistemas en contacto en el Paraguay.

También creo que puede estar íntimamente relacionada con este elemento causal, al menos parcialmente, la selección efectuada en el español paraguayo del morfema le como representante único de las funciones de

104 Véanse en especial los trabajos de Marcos A. Morínigo citados en nota 27.

105 Cfr. B. Mel.IA, «Hacia una 'tercera lengua' en el Paraguay», en Estudios Paraguayos, 2 (2), 1974, págs. 31-71.

106 Véanse L. S. RÉVAH, "Formation et évolution des parlers judéo-espagnols des Balkans", en Actes du Xe Congrès International de Linguistique Romane, III, Paris, 1964, págs. 1.351-1.371. También mi propio trabajo, "La desfonologización de $/ R /-/ \bar{R} /$ en el dominio lingǘstico hispánico", incluido ahora en Estudios lingüisticos hispanicos, afrohispánicos y criollos, Madrid, 1978, págs. 69-79.

107 A diferencia de lo que ocurre en el sistema verbal, el paradigma nominal del guaraní es (salvo en puntos concretos) poco complejo. Véase su sistema pronominal personal en ANTONio GuAsch, El idioma guarani, Asunción, 1976, págs. 96-104.

108 Art. cit., en nota 17. 
objeto directo e indirecto en forma átona en la tercera persona pronominal.

En efecto, en el guaraní paraguayo o coloquial (no en el guaraní clásico y tribal, en los que no se dan estos hispanismos) los morfemas la y lo, préstamos del castellano, son empleados en funciones perfectamente fijadas, como artículo singular el primero (la mitá = el muchacho) y como artículo plural el segundo (lo mitá = los muchachos) y también, en el caso de la, como equivalente a lo que, la que, los que, las que, que y a locuciones adverbiales de ámbito semántico muy amplio $\mathrm{y}$, a veces, difícilmente traducibles ${ }^{109}$. Dada la estrecha convivencia de las estructuras gramaticales del castellano y del guaraní coloquial en la competencia de los hablantes paraguayos bilingües es perfectamente explicable que, para su utilización como pronombre personal átono objeto de tercera persona dentro del paradigma linguíístico español, hayan seleccionado la forma le con preferencia a $l o, l a$, las cuales, además de estar dotadas de su significado articular en castellano, se empleaban también en guaraní paraguayo con valores funcionales propios mientras que $l e$, por el contrario, estaba, en este sentido, "vacante» y podía ser utilizado con menor posibilidad de ambigüedad funcional y semántica.

Respecto a la desmorfologización de les, forma sin duda existente en el paradigma castellano originario del leísmo paraguayo, creo que puede ser justificada, además de por la acción de los procesos mencionados de simplificación periférica e interferencia de sistemas, por el efecto de condicionamientos derivados de tendencias claramente actuantes tanto en el español como en el guaraní. Me refiero en particular, por lo que toca al castellano, a la posible analogía con se, ya apuntada por Kany ${ }^{110}$, a la "economía morfológica» que J. J. Montes ${ }^{111}$ considera decisiva en numerosos ejemplos de les $>$ le que se dan en gran número en el español americano y también, aunque más raramente, en el español europeo y a la tendencia fonética hacia la debilitación o eliminación de -S final en el castellano rioplatense, en especial en el área paraguaya ${ }^{112}$.

109 Por ejemplo: Upeicha la rejapo vae'rã (= Así es como debes hacer); Yvate la oĩ (va) (= Arriba es donde está); Hogape la jaháta (va) (= Es a su casa a donde vamos a ir).

110 Ob. cit., en nota 14.

111 «Le por les ¿un caso de economía morfológica?», en Thesaurus, 20, 1965 (cito por separata).

112 Véase Marfa Beatriz Fontanella De WeinBerg, Análisis sociolingüistico de un aspecto del español bonaerense, Bahía Blanca, 1972; “Comportamiento ante -S de hablantes femeninos y masculinos del español bonaerense", en Romance Philology, 27, 1973, págs. 50-58 y «Aspectos sociolingüísticos del uso de -S en español bonaerense», en Orbis, 23, 1974, págs. 85-108. 
Esta última tendencia ha podido, por otra parte, ser reforzada por la peculiar estructura fónica de la sílaba en guaraní, idioma en el cual sólo se admite como elemento implosivo postnuclear la consonante nasal ${ }^{113}$.

El examen que he realizado en estas páginas de los factores que, en su interacción, han dado lugar al desarrollo de un rasgo morfológico característico del área lingüística paraguaya demuestra que este fenómeno concreto no hubiera podido ser explicado convenientemente sin la utilización de la metodología derivada del concepto de «causación múltiple». Creo que la aplicación de este principio metodológico en otros estudios similares al que aquí nos ha ocupado no puede dejar de producir excelentes resultados en el extenso campo de investigación que configuran las zonas americanas de habla española.

\section{GERMAN DE GRANDa}

Universidad Autónoma de Madrid Embajada de España en Malabo.

113 Cfr. Sara Delicia Villagra de Garcfa, «La palabra. Sus clases morfológicas en la lengua guaraní», en Suplemento Antropológico. Universidad Católica, 5 (1-2), 1970, págs. 163-200 y J. P. CAPRILE, "Essai de phonologie du guarani commun du Paraguay», en Cahiers des Amériques Latines, 2, 1970. También E. Grfgores y J. A. Suarez, A Description of Coloquial Guarani, La Haya, 1967. 